\title{
CORRELATING GRAPH THEORY TO A SWITCHING NETWORK
}

\author{
Mythili $\mathbf{V}^{1}$, Rajalakshmi $\mathbf{R}^{2}$, Little Femilin Jana $\mathbf{D}^{\mathbf{3}}$ \\ ${ }^{I}$ Assistant Professor, Prince Shri Venkateshwara Padmavathy Engineering College, Affiliated to Anna University, \\ Tamil Nadu \\ ${ }^{2}$ Assistant Professor, Prince Shri Venkateshwara Padmavathy Engineering College, Affiliated to Anna University, \\ Tamil Nadu \\ ${ }^{3}$ Assistant Professor, Prince Shri Venkateshwara Padmavathy Engineering College, Affiliated to Anna University, \\ Tamil Nadu
}

\begin{abstract}
Graph theory is a delightful playground for the exploration of proof techniques in almost all fields of mathematics. Here in this paper let us see its practical application to a switching network. Suppose we are given a box that contain a switching network consisting of some switches and they can be turned on or off from outside, we determine how the switches are connected inside the box, without opening the box, of course with the help of graph theory.
\end{abstract}

Key words: Identity matrix, redundant circuit, construction of a graph, switching network, orthogonal matrices, ring sum.

\section{INTRODUCTION}

Graph theory has a wide range of applications in engineering, electrical network analysis, circuit layout, data structures, operations research, social sciences etc because of its inherent simplicity. It also plays an important role in several areas as switching theory. It begins with very simple geometric ideas and has many powerful applications.

\section{Some Useful Definitions}

\section{Definition 1:}

Let the number of different circuits in a graph $\mathrm{G}$ be $\mathrm{q}$ and the number of edges in $\mathrm{G}$ be e. Then a circuit matrix $B=$ $\left[b_{i j}\right]$ of $G$ is a $q$ by $e,(0,1)$ - matrix defined as follows:

$b_{i j}=\left\{\begin{array}{l}1, \text { if the } i^{\text {th }} \text { circuit includes } j^{\text {th }} \text { edge } \\ 0, \text { otherwise }\end{array}\right.$

\section{Definition 2:}

A sub matrix of a circuit matrix in which all rows correspond to a set of fundamental circuits is called a fundamental circuit matrix.

\section{Definition 3:}

The ring sum of two graphs $G_{1}$ and $G_{2}$ written as $G_{1} \oplus G_{2}$ is a graph consisting of the vertex set $V_{1} \cup V_{2}$ and of edges that are either in $G_{1}$ or $G_{2}$ but not both. For example consider

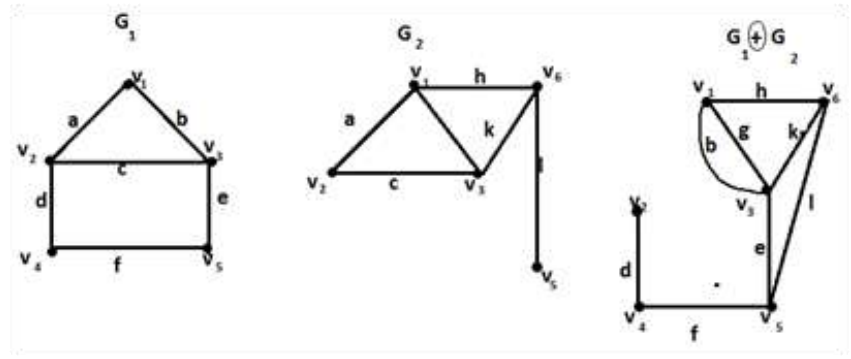

Assume that a box contains a switching network consisting of eight switches a,b,c,d,e,f,g and h. The switches can be turned on or off from outside. Let us see how to determine the switching connection inside the box, without opening the box.

First connect a lamp at the available terminals in series with a battery and an additional switch $\mathrm{k}$ as shown below:

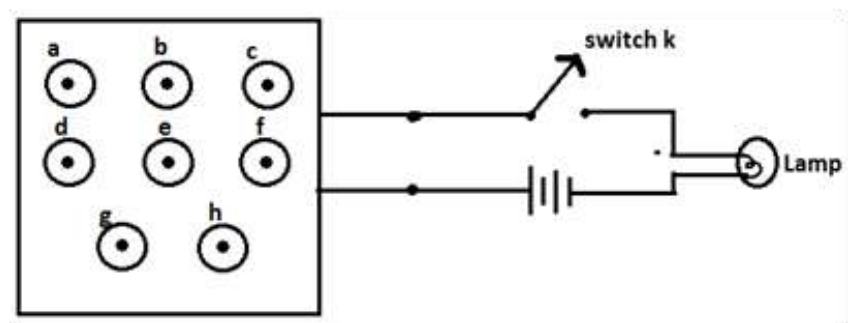

Let us assume that the following eight combinations light up the lamp.
1. $(\mathrm{a}, \mathrm{b}, \mathrm{f}, \mathrm{h}, \mathrm{k})$
2. $(\mathrm{a}, \mathrm{b}, \mathrm{g}, \mathrm{k})$
3. $(\mathrm{a}, \mathrm{e}, \mathrm{f}, \mathrm{g}, \mathrm{k})$ 

4. $(\mathrm{a}, \mathrm{e}, \mathrm{h}, \mathrm{k})$
5. (b,c,e,h,k)
6. $(\mathrm{c}, \mathrm{f}, \mathrm{h}, \mathrm{k})$
7. $(\mathrm{c}, \mathrm{g}, \mathrm{k})$
8. $(\mathrm{d}, \mathrm{k})$

Consider the switching network as a graph whose edges represent switches. We can assume that the graph is connected and has no selfloop. Since a lit lamp implies the formation of a circuit; we can regard the preceding list as a partial list of circuits in the corresponding graph. With this list we form a circuit matrix.

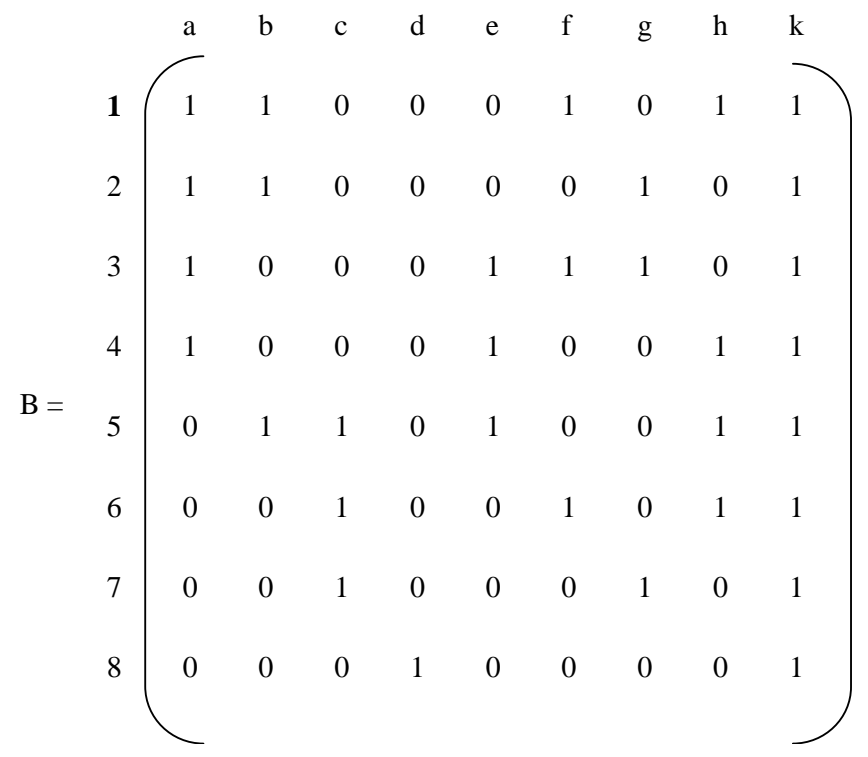

Next to simplify the matrix, we should remove the obviously redundant circuits. Observe that the following ring sum of circuits give rise to other circuits.

\section{$(a, b, g, k) \oplus(c, f, h, k) \mp(c, g, k)=(a, b, f, h, k)$ $(a, b, g, k)+(a, e, h, k)+(c, g, k)=(b, c, e, h, k)$ $(a, e, h, k) \biguplus(c, f, h, k) \biguplus(c, g, k)=(a, e, f, g, k)$}

Therefore we can delete the first, third and fifth rows from matrix $\mathrm{B}$, without any loss of information. Remaining is a 5 by 9 matrix $B_{1}$.

$$
\mathrm{B}_{1}=\left(\begin{array}{ccccccccc}
\mathrm{a} & \mathrm{b} & \mathrm{c} & \mathrm{d} & \mathrm{e} & \mathrm{f} & \mathrm{g} & \mathrm{h} & \mathrm{k} \\
1 & 1 & 0 & 0 & 0 & 0 & 1 & 0 & 1 \\
0 & 0 & 0 & 0 & 1 & 0 & 0 & 1 & 1 \\
0 & 0 & 1 & 0 & 0 & 0 & 1 & 0 & 1 \\
0 & 0 & 0 & 1 & 0 & 0 & 0 & 0 & 1
\end{array}\right)
$$

Our next goal is to bring matrix $B_{1}$ to the form $B_{f}=\left[I_{f r} / B_{r}\right]$. For this we interchange columns to get $\mathrm{B}_{2}$ :

$$
\begin{aligned}
& \mathrm{B}_{2}=\left(\begin{array}{ccccc:cccc}
\mathrm{b} & \mathrm{e} & \mathrm{f} & \mathrm{g} & \mathrm{d} & \mathrm{a} & \mathrm{c} & \mathrm{h} & \mathrm{k} \\
1 & 0 & 0 & 1 & 0 & 1 & 0 & 0 & 1 \\
0 & 1 & 0 & 0 & 0 & 1 & 0 & 1 & 1 \\
0 & 0 & 1 & 0 & 0 & 0 & 1 & 1 & 1 \\
0 & 0 & 0 & 1 & 0 & 0 & 1 & 0 & 1 \\
0 & 0 & 0 & 0 & 1 & 0 & 0 & 0 & 1
\end{array}\right) \\
& \mathrm{B}_{3}=\left(\begin{array}{ccccc:cccc}
\mathrm{b} & \mathrm{e} & \mathrm{f} & \mathrm{g} & \mathrm{d} & \mathrm{a} & \mathrm{c} & \mathrm{h} & \mathrm{k} \\
1 & 0 & 0 & 0 & 0 & 1 & 1 & 0 & 0 \\
0 & 1 & 0 & 0 & 0 & 1 & 0 & 1 & 1 \\
0 & 0 & 1 & 0 & 0 & 0 & 1 & 1 & 1 \\
0 & 0 & 0 & 1 & 0 & 0 & 1 & 0 & 1 \\
0 & 0 & 0 & 0 & 1 & 0 & 0 & 0 & 1
\end{array}\right)
\end{aligned}
$$

Adding the fourth row in $\mathrm{B}_{2}$ to the first, we get $\mathrm{B}_{3}$. An Orthogonal matrix to $\mathrm{B}_{3}$ is $\mathrm{M}=\left[-\mathrm{F}^{\mathrm{T}} / \mathrm{I}_{4}\right]=\left[\mathrm{F}^{\mathrm{T}} / \mathrm{I}_{4}\right]$

$$
\text { Thus M }=\left(\begin{array}{lllll:llll}
\mathrm{b} & \mathrm{e} & \mathrm{f} & \mathrm{g} & \mathrm{d} & \mathrm{a} & \mathrm{c} & \mathrm{h} & \mathrm{k} \\
1 & 1 & 0 & 0 & 0 & 1 & 0 & 0 & 0 \\
1 & 0 & 1 & 1 & 0 & 0 & 1 & 0 & 0 \\
0 & 1 & 1 & 0 & 0 & 0 & 0 & 1 & 0 \\
0 & 1 & 1 & 1 & 1 & 0 & 0 & 0 & 1
\end{array}\right)
$$

Before $M$ can be regarded as a reduced incidence matrix, it must have at most two $\mathrm{I}^{\mathrm{s}}$ in each column. This can be achieved by adding $(\bmod 2)$ the third row to the fourth in $\mathrm{M}$, giving $\mathbf{M}^{1}$.

$$
\mathrm{M}^{1}=\left(\begin{array}{ccccccccc}
\mathrm{b} & \mathrm{e} & \mathrm{f} & \mathrm{g} & \mathrm{d} & \mathrm{a} & \mathrm{c} & \mathrm{h} & \mathrm{k} \\
1 & 1 & 0 & 0 & 0 & 1 & 0 & 0 & 0 \\
1 & 0 & 1 & 1 & 0 & 0 & 1 & 0 & 0 \\
0 & 1 & 1 & 0 & 0 & 0 & 0 & 1 & 0 \\
0 & 0 & 0 & 1 & 1 & 0 & 0 & 1 & 1
\end{array}\right)
$$


Matrix $\mathrm{M}^{1}$ is the reduced incidence matrix .The incidence matrix A can be obtained by adding a fifth row to $\mathrm{M}^{1}$ such that there are exactly two $\mathrm{I}^{\mathrm{S}}$ in every column.

$$
\mathrm{A}=\left(\begin{array}{ccccccccc}
\mathrm{b} & \mathrm{e} & \mathrm{f} & \mathrm{g} & \mathrm{d} & \mathrm{a} & \mathrm{c} & \mathrm{h} & \mathrm{k} \\
1 & 1 & 0 & 0 & 0 & 1 & 0 & 0 & 0 \\
1 & 0 & 1 & 1 & 0 & 0 & 1 & 0 & 0 \\
0 & 1 & 1 & 0 & 0 & 0 & 0 & 1 & 0 \\
0 & 0 & 0 & 1 & 1 & 0 & 0 & 1 & 1 \\
0 & 0 & 0 & 0 & 1 & 1 & 1 & 0 & 1
\end{array}\right)
$$

From the above incidence matrix A we are able to construct the graph and hence the corresponding switching network as shown below.
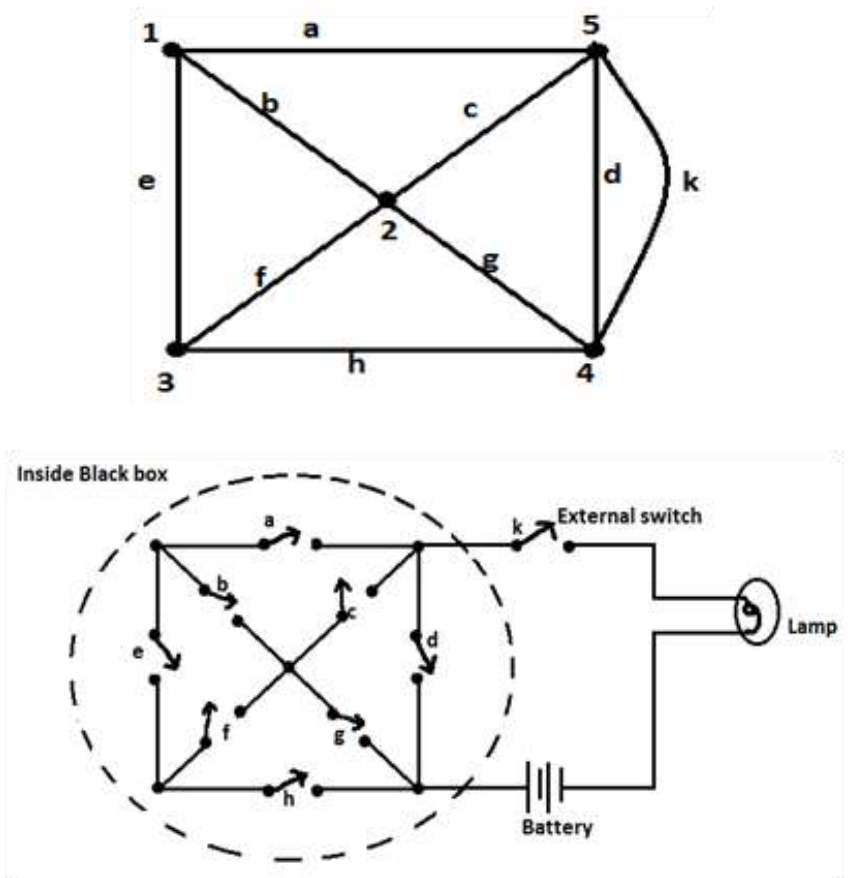

\section{CONCLUSION}

Thus by removing the obviously redundant circuits and by constructing the incidence matrix, we see that the corresponding switching networks inside a box can be found without opening it.

\section{REFERENCES}

[1]."NARSINGH DEO" -Graph theory with Applications to Engineering and Computer Science, PHI Learning Pvt. Ltd., New Delhi.

[2]."DOUGLAS B.WEST"- Introduction to Graph Theory, University of Illinois-Urbana.

[3]."JOE L.MOTT. ABRAHAM KANDEL THEODORE P.BAKER"-Discrete Mathematics for Computer Scientists and Mathematicians.
[4].’J.P.TREMBLAY, R.MANOHAR" - Discrete Mathematical Structures with Applications to Computer Science- Tata McGraw Hill Publishing Company Ltd. 